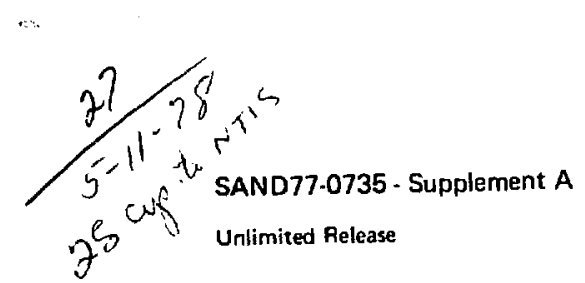

\title{
A Materials Information Data Bank
}

\section{MASTER}

Keith E. Mead

s

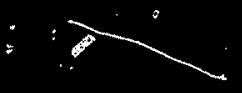

ti

$\Rightarrow$

25

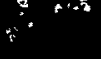


SA.VDT7-0735-Supplenir.n1 I

l'nIimitis! Releats.

l'einted Hitreh 1978

\section{NOTICE}

PAOTINNS OF THIS REPORT ARE ILLEEIDLE it has kran rparod "ced from the oest drailable cr.y te permit the breadost poserble avait ability.

A MATERIALS INFORMATION DATA BANK

Keith E. Mead

Polymer Science and Engineering Division 5812

Sandia Laboratories

Albuquerque, $\mathrm{NM} B 7185$

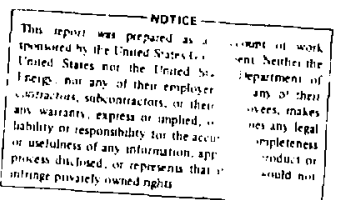

ABSTRAC'T

This supplement to SAND77-0735 is a working paper describing in detail the procedures for entering and retrieving information Irom the 31 aterials luformation Data Bank. 


\title{
CONT ENTS
}

\author{
I INTRODUCTION \\ Purpose \\ I OPERATIONAL PROCEDURE \\ Preparation of Input Information \\ Procedure for Entry of Information \\ Materiala Numbering Syutem \\ Procedure for Information Retrleval \\ APPENDIX A - Examples of Information Retrieual Routines
}

\begin{tabular}{c} 
Page \\
\hline 7 \\
7 \\
7 \\
7 \\
8 \\
8 \\
9 \\
17 \\
31
\end{tabular}

TABLES

Table

I Guide to Recording a NEW MATBRLAL RECORD

II Guide to Recording ADDITIONS TO DATA IN FILE

III Guide to Recording the TEST SUMMARY RECORD

IV Information Retrieval Routines

A-1 Query Options

A-2

DUMPALL

$A=3$

DUMPIT

20

DUMPAIR

$A-4$

ALINAME

A-6 Batch Output ALIBAD-1

A-7 ALLBAD-2

A-8 ALLAPPL

A-9 DUMPCAT

A-10 DUMPUSE

A-11 DUMPAPL

B-1 Material Information Data Bank Systems Procedure 


\section{ILLUSTRATIONS}

Figure

Page

1

Sample Entrie日: NEW MATERIAL RECORD - SA7195-VFC(12-77)

10

2 Sample Entries: ADDITIONS TO DATA IN FILE - SA7195-VFB(2-78)

12

3 Sample Eitries: TEST SUMMARY RECORD - SA7195-VFB(2-78)

14

B-1 MCSIS Data Input Flow Chart

33 


\section{INTRODUCTION}

\section{Purpose}

To assist in materials gelection, a computerized materials data bank has been established. In addition to references on personnel and documents, this data bank provides annotated information on materials so that the deaigner and materials engineer can draw on it for guldance in selecting materiala. The primary purpose of the data bank is to provide materiale compatibility data. However, the structure of the syatem permite the date bank to be uged for atorage and retrieval of general materials intormation.

\section{OPERATIONAL PROCEDURE}

\section{Preparation of Input Information}

aput information is prepared by entering appropriate data into two Sandia forms. They are:

1. SA7195-VFC (12-77) NEW MATERLAL RECORD (prepared only by the Materials Laboratory)

2. SA7195-VFB (2-78) TEST SUMMARY RECORD and ADDITIONS TO DATA IN FILE (prepared by the test enginaer or author)

These forms have entry level numbers in the first column of each representation of an IBM card. These entry level numbera are referred to in aubsequent explanations of procedure. For convenience, Ingtructions for preparing the forms are printed on the page opposing the respective sample form shown later is this document.

For each unique materials tested, one-time entries are made into the bank with NEW MATERIAL AECORDS (Figure 1). Thee recorde are prepared only by Materials Laboratory personnel. The first column of each IBM card contains the entry number. The second column containe the card number for that entry. The third column contains a control for inputting new information or for correcting existing information. Information placed in the bank by this record includes four entry levels, material name and oynonyms, material category, material contents, and, where applicable, materia! formula. 
Each NEW MATERLAL RECORD is coordinated by means of a reference number assigned to that material by the Materiale Laboratory, e.g. . M05502. All information that has any bearing on that material is controlled and correlated in the bank by this reference number and need not be entered again r.o matter how many other entries are subsequently made.

Each time a material is subjected to a test, an entry is made, using the form for ADDITIONS TO DATA IN FlLE, entry level No. 5 (Figure 2). This entry is correlated with the reference number assigned that material by the Materials Laboratory. Information entered in this form consists of the material application, material use or form, and the test reference number. This number coordinates entry No. 5 with entry No. 6, TEST SUMMARY RECORD, which is an abstract of test iniormation. A sample of TEST SUNMARY RECORD is shown in Figure 3.

\section{Procedure for Entry of Information}

When a compatibility test or a single material evaluation is completed, an entry(s) describing the test is marle into the bank. This information is provided by the test engineer who prepares the TEST SUMMARY RECORD, entries 6-1 through 6-5 (Eigure 3). Detalled instruction for the preparation of input information are given in a table on the page opposite the appropriate sample entry (Tables 1 , II, and $1 \mathrm{Il}$ ). The test engineer also prepares ADDITIONS TO DATA IN FILE, entries 5-1 through 5-n ( $n$ is the total number of materials involved in the test). If the materials are elther all compatible or all incompatible, only a single TEST SUMMARY RECORD is required. However, if some are compatible and others incompatible, then a TEST SUMMARY RECORP is required for each set, one for the compatible and another for the incompatible materials.

Prepared TEST SUMMARY RECORD forms along onth a copy of the documented data are submitted to compatibllity coordinators of an interested organization. They review the data, assign a unique test reference document number to each TEST SUMMARY RECORD, and enter material numberg. These numbers are used by the bank to coordinate and control all Information on that particular test. NEW MATERIAL RECORDS, as required by materials listed on the ADDITIONS TO DATA IN FILE form, are prepared by the Materials Laboratory. The data is then submitted to the Data Operations Division 9626 who prepare IBM cards for batch entr. into the bank.

\section{Materials Numbering System}

All materlal mumbers are prefixed with $M$ and have five digits (Mxcoxi). NEW MATERIAL RECORD forms can be prepared elther at the time of need or ahead of time. The number is asgigned to a materlal on this form. NEW MATERIAL RECORDS are prepared by Materials Laboratory speclaliste in the : 2 risie material disciplines. To provide open-ended freedom to 
assign numbers, material reference numbers are given to the various disciplines in hlosks. This system provides for 200 material categories with 500 names to the category. The hlocks are:
1. Metal
1 to 20,000 or 40 possible categaries
2. Organic Materials
20,001 to 40,000
3. Ceramics
40,0001 to 60,000
4. Available
60,001 to 99,999

Procedure for Information Retrieval

During the early life of the data bank, retrieval will be by request through compatihility coordinators. AB data becomes extensive and the probabllity of retrieving useful information increases along with confidence in the program, direct retrieval by engineers will be permitted.

Retrleval will be either Interactive for small amnunts of information or batch for more lengthy output. Information retrieved from the data bank should be interpreted cautiously. A reference indicating that materials are cither compatible or incompatible represents the conclusion of the test engineer and then only under the conditions and environment of his test. Interpreting information with respect to particular needs may require consulting with Materials Laboratory personnel.

Table IV is a listing of information retrieval routines. The programs are listed in the or: $: \mathrm{r}$ of priority which has been established for developing the data bark. The list provides a versatile set of routines for directing retrieval toward either broad or specific interests. All routines listed in this table are currently functional. Examples of retrieved information are included in Appendix 1. Appendix B contains a now chart for input of data. Also included is a detailed list of the sequence of input events showing who has the responsibility to complete each necessary step. 
date:

to: Materlals Compatiblilty Coordinatine froup (MCCG) - 5810

rron:

re: New Matcrial Record (one-tirue entry)

Test Report Title

and Date: $4 / 20 / 7 / 7$

Please note that shaded areas arc for MCCG use.

Complete instructions for entries are printed on reverse side.

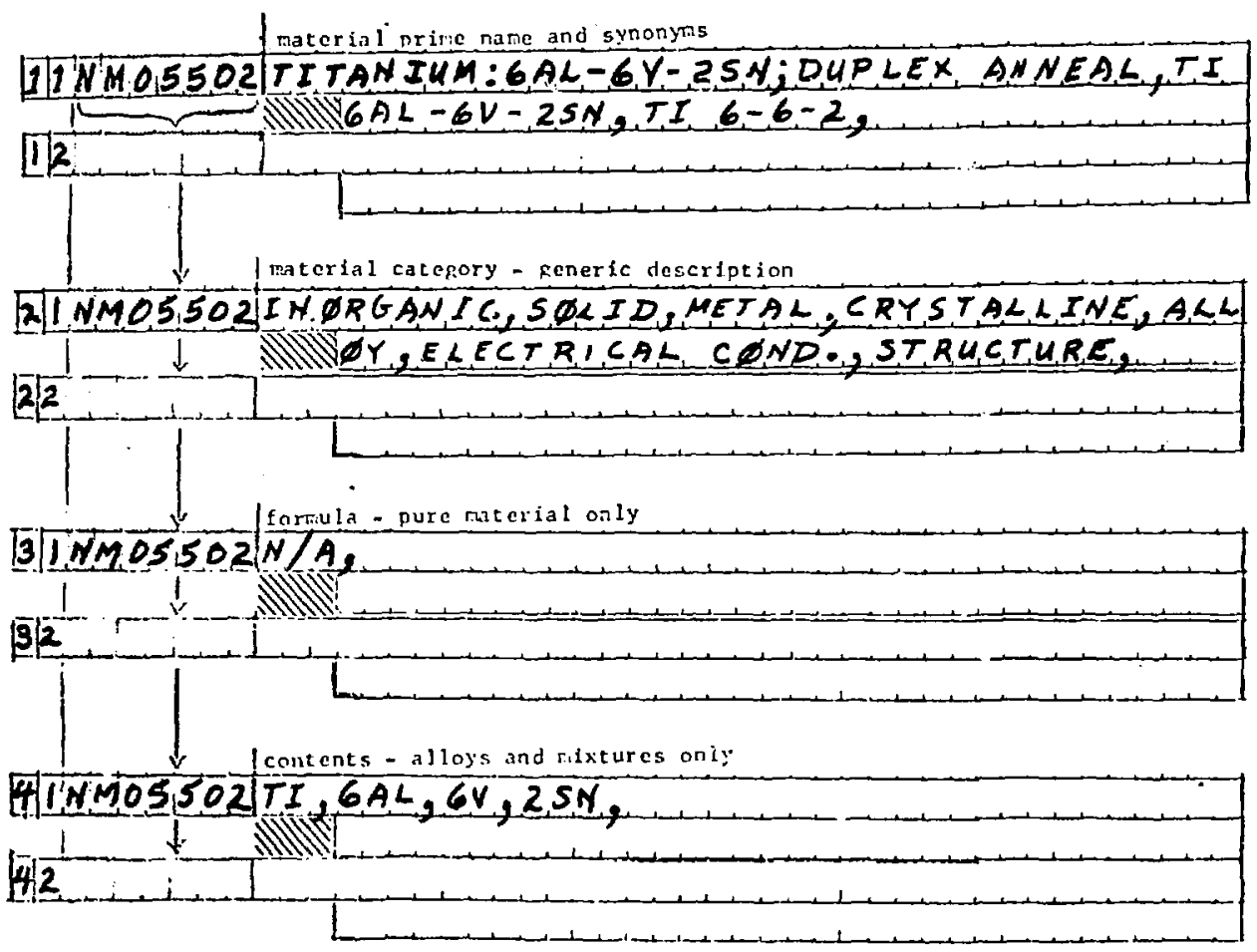

Figure 1. Sample Entries: NEW MATERIAL RECORD

SA $7135-17 \mathrm{FC}(12-77)$ 
TAHLE I

Guide to Hecording a NEW MATEHAI. HECOMI

A. General instruations

1. Start the data in the left most column of the field.

2. A name may consist of one or more words with a single space between words but the total number of cliaracters in a name may nol exceed 40.

3. When ent sring a series of names or terms in a field, separate them filt; a comma bul Jo noi luavi a ypace after the comma.

4. liner a comma after the last character in each field.

13. Specific Instructions - 1st ENTKY * Material prime name and synonymy

1. The narr e is to be definitive: the name and following avnonyms musil end with a comms. All rommanly used synotyms should be entered as space per mits.

2. The nat e may be divided into a maximum of three parts by : colon and a jemicolon so that multiple. level searching is practical (see TEST SLMIMARY RECOHU.

Hxamples: $\quad$ Name

ALURIINT:At:7075:T7351, At.7075,7075AL,

SILICONL:GE RTV 610. GE 610, RTV 620,

EPOXY: LPCN B2B Z;3M GMB, I:PON B2B Z/GMTB,

2nd LNTIFy - Genertic name, material category - generic description. This entry pernath starrhing lay generic characterigtics.

This entry is to include as many of the namey irom the tollowing lists as metessar, fo compli:ly deseribe the material. Additional descriptors ale sought.

cieneric vames

\begin{tabular}{lll} 
& Cicneric Vames & \\
\hline Organic & Polymer & Llastonice \\
Inorganic & Compound & Thermoset \\
Organometallic & Motal & Thermoplastic \\
& Ceramic & \\
& Glass-ceramic \\
& Cilass
\end{tabular}

Generic form or likysical Characteristic

\begin{tabular}{|c|c|c|}
\hline $\begin{array}{l}\text { Cias } \\
\text { l.iquid } \\
\text { Solis }\end{array}$ & $\begin{array}{l}\text { Croystalline } \\
\text { Foam } \\
\text { Film } \\
\text { Composte } \\
\text { Glass } \\
\text { Generic Functio }\end{array}$ & $\begin{array}{l}\text { Pure } \\
\text { Mixture } \\
\text { Alloy }\end{array}$ \\
\hline $\begin{array}{l}\text { Catalyst } \\
\text { Adhesive } \\
\text { laminate } \\
\text { Structure } \\
\text { Lubricant } \\
\text { Coolant }\end{array}$ & $\begin{array}{l}\text { dlolding } \\
\text { Thermal Ins. } \\
\text { Thermal Cond. } \\
\text { flectricil Ins. } \\
\text { lilectrical Cond. } \\
\text { Sealant } \\
\text { l'otting }\end{array}$ & $\begin{array}{l}\text { Costing } \\
\text { Electroplate } \\
\text { Electrolessplat: } \\
\text { IEvaporative } \\
\text { Dip } \\
\text { Spras } \\
\text { Cisting }\end{array}$ \\
\hline
\end{tabular}

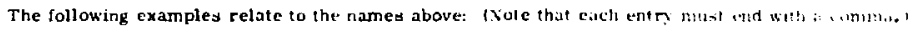

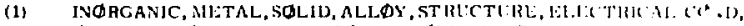

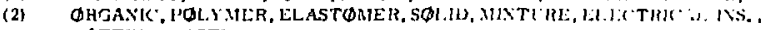

POTTINC, CASTING.

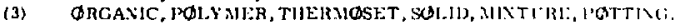

ELECTRICAL INS. , A DIESIVI, SEAI. ANT,

3rd liNTHS - Vormula

1. Linter the chemistry of pure materials:

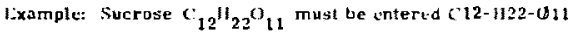

vote: When not applicable, as for the name examples above, entur with.

4th EXTHY - Material Conlents

1. Enter the chemistry or ingredients of mixtures and alloys.

The following examples relate to the prime name and categories above; each entry must enul with a comma.

(1) AL, $1,6 \mathrm{CU}, 2,5 \mathrm{MG}, 0.2 \mathrm{MN}, 5.6 \mathrm{ZN}, 0,3 \mathrm{Cl}$,

(2) POLYDIMETHYL SILOXANL VINYL TERMINATEW, MITIII, IN IMUKAN, SILOXANE, CHLGRQPLATINIC ACID, FILLER.

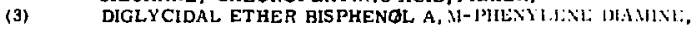
METHY LENE DIANILINE, SILIC:A, SIO2, 


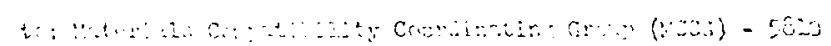

$\therefore \cdots$

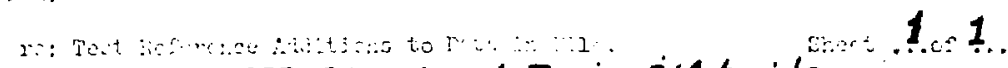
E77 Structural Design giMaterials ur Review Meting, sept. 8-10, 1976

TITANI UM:GAL-GY-2SN;DUPLEX ANMEAL!

S1NMOSSO2R $770329 C \mathrm{CCMNWT7,}$

"if

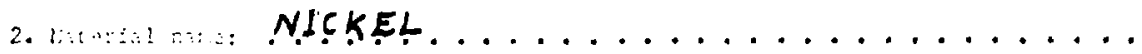

$51 N M O 450)$

fon: $\quad$ iWIRE

3. ......... STAINLESTS STEEL:30\%;0.5H, . . . . . . .

51 NMO1 001 hey

(1, M

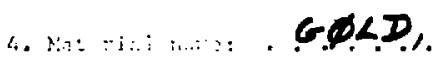

SLNMOTOOI TEx

5. :At:: GOPPER,

51 MO700

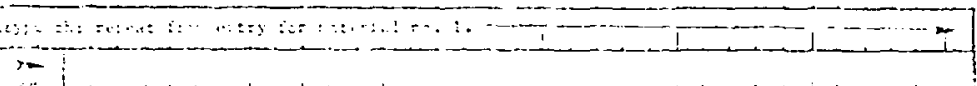

tc: : :

6. 1 :

51 NM 0.0002 rey

Figure 2. Sample Entries: ADDITHONS TO DATA IN FILE

SAT1 $\overline{0}-V F(3(2-7)$. 
TAIBLE II

Gulde to Recording ADDITIONS TO DATA IN FILE

A. General Instructions

1. Prepare this form after the TEST SUMMARY RECORD is prepared.

2. Start $i$. data in the left most column of eac.. fleld.

3. A name may consist of one or more words with a single space between words but the total number of characters in a name may not exceed 40 (see NEW MATERIAL. RECORD;.

4. Enter a comma after the last character in each fleid.

B. Specific Instructions

1. On the numbered lines $(1,2$, et 2,$)$ print all material names used in the tast, one name per numbered line (as listed in the TEST SUMMARY RECORD). This entry is not computerized; it is used to assign the material record number.

2. The "test roference number" entries refer to the same entries on the TEST SUMMF .ZCORD.

3. For "application" fleld, enter ihe weapon system or equipment title as the "final ass'y, " end It with a comma, then enter the major component (MC) or other device name as "subass'y." (Note that this entry and the "test reference number" need be entered only once for the first material record entry, as it is the same for all materials in the test. It is entered for the recoris of the other tested materials during keypunching.)

4. The "form or functional use" field is a separate entry for each material tested and is intended to reflect the use or form of the material in this test. This ciescription enables selective retrieval from the materini record(s) of a list of materlals by use or by form. Within the limit of the field length this eniry may include one or more uses or forms but will be searchable for only one name at a time; each entry must end with a comma.

Examples: (1) MØLDED STRUCTURE,

(2) WIRE, SPRING,

(3) PØWDER COMPACT, BEARING,

(4) RøLLED RING FøRGING, 
arte:

to: Materials Comptibility Coordinaling Groul (MCCG) - 5810

rron:

re: Test Surrnnily Record

icst. Report Titls B77 Structural DesignedMaterials and Datc: Review Meeting, Sept, $8-10,1976$

Plcase note that shuded arens are for HCCG use.

Complete instructions for cntries are printed on jeverse side.

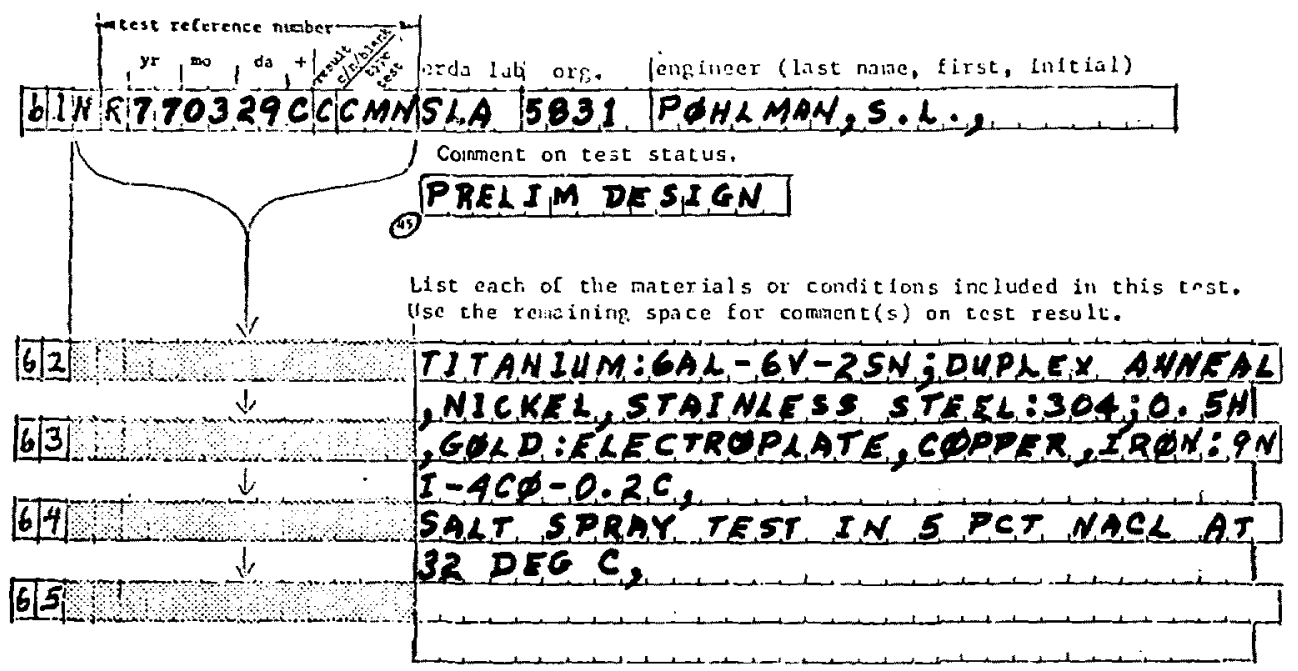

Figure 3. Sample Entries: TEST SUMMARY RECORD

SA7105-VFB(2-78) 
A. General Instrustions. This data record is in IBM card format.

1. Start the data in the left most column of the field.

2. A name may consist of one or more words with a single space between wirds but the total number of characters in a name may not exceed 40 .

3. When entering a series of names or terms in a field, separate them with a comma but do noi leave e apace arter the comria.

4. Enter a comma after the lagt character in each fifld.

B. Specific Instrustions

1. Test Reference Number. No entry is required in the shaded area.

a. Enter the test results $C, N$, or leave it blank. Use a separate form

for each of these entries.

C - This record to for materials found to be compatible

N - This record is for materials found to be incompatible

Blank - Indicates a phyaical or mechanical property test of a single material (Test Type entry must be PRP)

b. The last three columns define the type of test performed. Enter CMN, GRP, or PRP.

CMN - A test involving a singie material paired with one or more other materials. The material common to all MUST be the first listed in entry 6-2.

GRP - A test of several materials together to determine their joint compatibility.

PRP - A test of one material under one or more physical or mechanical conditions, e.g. , temperature, stress, etc. , to determirte its limits of satisfactory service (Test result entry MUST be blank)

2. DOE Laboratory or Contracior - Enter the abbreviation for the appropriate laboratory. Left justify.

Examples; SLL, SLA, LLL, LASL, GEND, BX, MD, Y-12, ORNL

3. Organization - Enter organization number. Left justify.

4. Engineer - Enter last name followed by a comma and then initials. Left justify.

5. Comment on test statug - This brief narrative entry (14 characters maximum) indicates the status of use of the material; each entry

Examples: (i) PRELIM DESIGN

(2) ${ }^{*}$ ATRL DEVELQP

(3) CYCLE 6 EVAL.

6. List of materials included in the test and comments on test results,

a. Cards 6-2 through 6-5 - Enter the names of all materials in the test. For every test labeled CMN (see B. $1 . \mathrm{b}$ above) the first material in entry 6-2 must be the common material.

Each name is to be definitive. A name may be divided into a maximum of three parts by using a colon betwe'n the first and second part and a semicolon between the 5 -cond and third part sa that multiple level searching is practical; each name must end with a comma.

Examples: (1) ALUMINUM:7075;T7351,

(2) SILIC $\varnothing N E: G E$ TRY 610

(3) EPQXY:EPQN B28 $z ; 3 M$ GMB,

b. Upon completing 6, a. above, go to the next card and the remaining space (1. e. . cards 6-3 through 6-5) may be used for an abstract of test results cr warning regarding restristions on material use. 
TABLA: IV

Information: l?etrieval Routines

l'rogram

Name

FITITT

RISTCORE:

At,1)IMI

MUINI

D) MIיז?

DIMPAIR

1)TMPNON

ALLNAME

$\triangle$ LLIBAD -

AITISAD-2

AI LAPPL

SLLTLST

DTMTCAT

DENTELE

13) $37 x(2)$

15

DI.MIPATI

DINTTR

5 l'rogram Function

lidit change - 'spdate MCSIS data bose, create hackup magrietic tape.

Thecover MCSIS data base from backup mianetic.

Dump entire MC:Sis dnta base on printer.

J'rovide menu of rucry programs with callup , Jabilities.

For a specific material nal $\mathrm{e}$, list one or rcre levels of informa tion finchud if test summaries!.

For specific pairs of niaterials, retrieve common test summarius.

For specific material, list all associated noncompatihle material and properties.

Generate a listing of all material prime names (alphabetic order) with associated material control number.

$9 \quad$ List by material prime name (alphabetic order) all nonconforming tests.

List all noncompatible tests (tesi reference number order) with associated material prime names.

List all material prime names associated with each application.

12 List all test sunmaries in MCSIS data base (test reference number order).

For speciflc material category, list associated material names (aIphabetic order).

Given a specific material form or use, list all associated material names (alphabetie orderl.

Given a specific Content, list all materials (alphabetic order) containing that Contents.

Given a specific applieation, list all associated nuterial names (alphabetic order) and test referelice numbers.

Given Lab/organization/engineer, list all associated test ceference numbers. \begin{tabular}{cc} 
Preg & Processing \\
Mode: & Prequency \\
\hline
\end{tabular}

B Weekly

$B \quad \wedge s$ required

$J / B \quad A s$ required

I Daily

I As required

I AE required

I As required

$\mathrm{I} / \mathrm{B} \quad \Lambda \mathrm{s}$ required

I/B As required

I/B As required

1/B As required

/B As required

I As required

I $\quad A s$ required

1 As required

I As required

I $\quad \Delta s$ required

B - Batch

I . Interactive

1/13 - Initiate batch from I terni 
APPENDIX A

Examples of Information Retrieval Routines 
TABLE A-1

Query Options

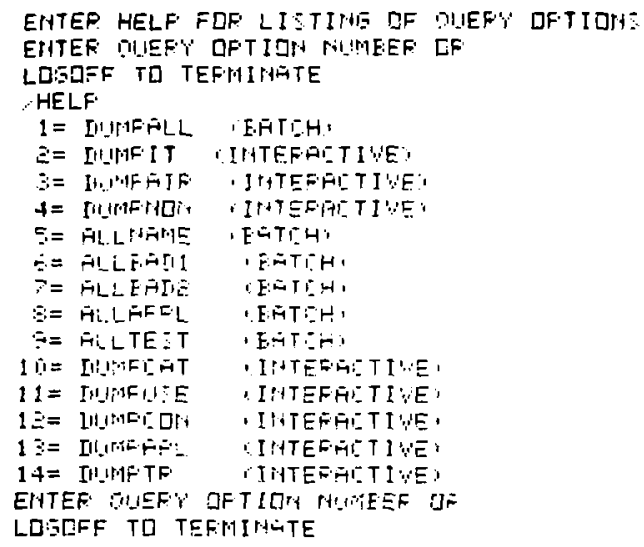


TABLE A-2

DUMPALL

A portion of she routine DUMPALL is reproduced here. It provides a listing of all six levels of information for each material and all references.

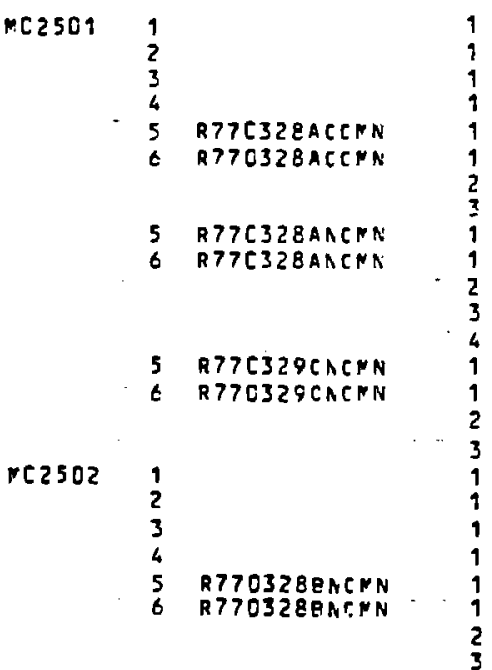

ALUNINUM:7075;T7351,7075AL,

INOREANIC, METAL, 5OL10, CRYSTALLINE, ALLOY, STRUCTURE, ELECTRICAL CCNO., NiA

$A L, 1, E C U, 2.5 N G, 0.2 \mathrm{NN}, 5.6 Z N, C .36 R$,

$W X:$,

AFT CCVER SEAL

SLF SEII POHLFAN:S.L.,

ALUMINUM:7075:T7\$5

SALT SPRAY TEST IN ZC PCT NAEL AT ?2 DEG C,

WXX.

AFT ECVER SEAL,

DEVELCPFENT, T,

SLA E831 PUHLKAN;S.L.$$
\text { DEVELC }
$$

ALUMINUM:7C75;T7ZST, STAINLESS STEEL:3C4;0.5H.COPPER:Z PCT BE,GCLO , NICKEL,

SALT SPRAY TEST IN ZC FCT MAEL AT 22 DEG C,

WYY,

SHEET,

SLA $5 E 31$ POHLFAN;S.L. PRELIN DESIGN,IGN,

TITARIUA: 6AL-EV-2SN:DUPLEX ANAEAL, ALUINUM:7075:T7351, CADNIUF,

SALT SPRAY TEST IN 5 PET NACL AT 32 DEG C,

ALUR INUM: $6061 ; T 6$.

SOLID, METAL, INCREANIC, CRYSTALLINE, ALLOY,STRUCTURE, ELETTRICAL COND.. NIA

AL, 1.OMG, 0.65J,0.25CU,C.25CR,

WZZ,

SLA' 5831 POHLPAN;S.L., PRELIF DESIGN, IGN,

ILUAINUA:6061;T6,STAINLESS STEEL:3C4:D.5H,

SALT SPRAY TEST 3.5 PCT HACL AT ROON TERPERATURE, 
TABLE A-3

DUMPIT

The DUMPIT (dump item) routine provides up to six levels of information for the material of interest.

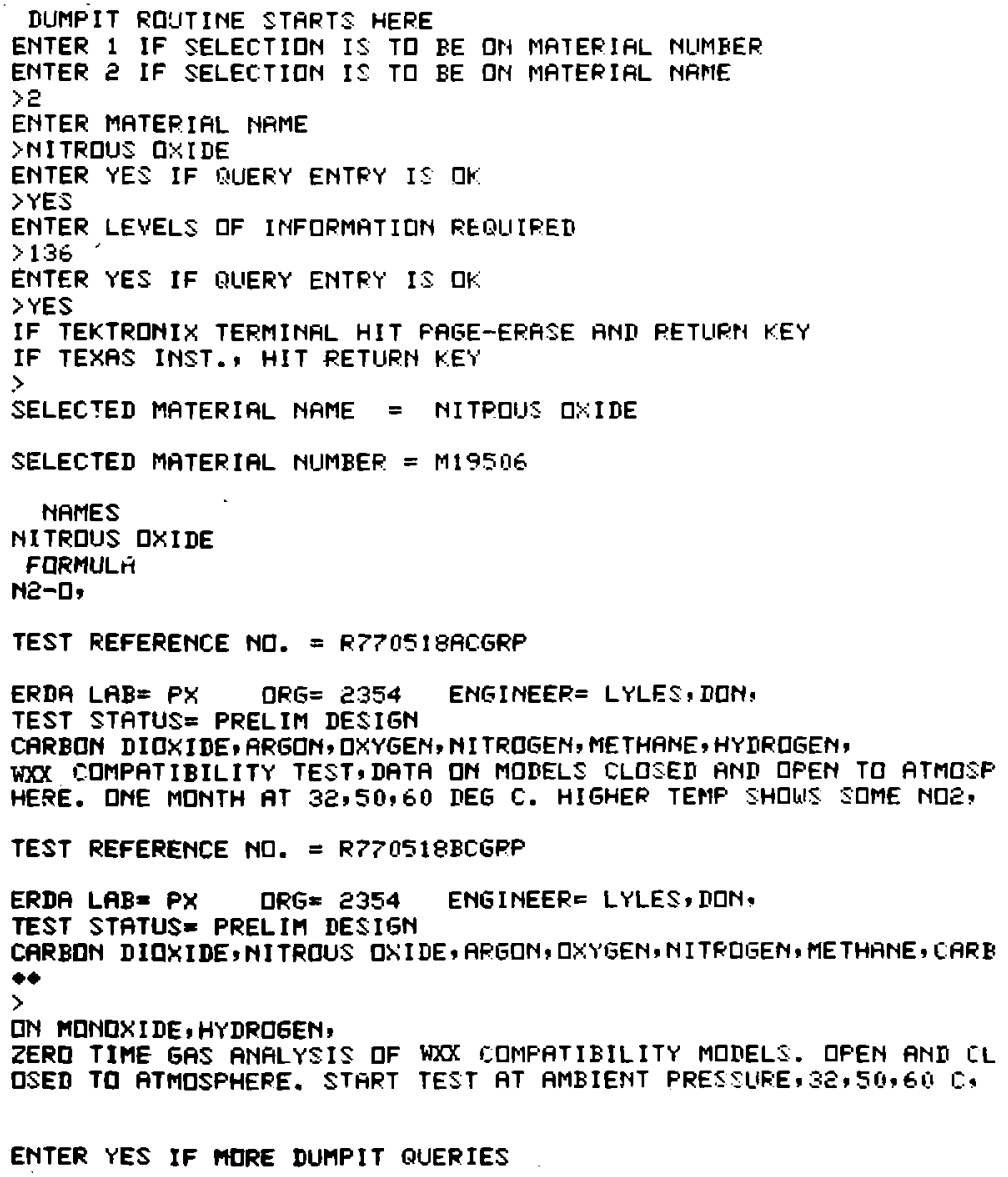

ENTER YES IF MORE DUMPIT QUERIES 
TABLE A-4

DUMPAIR

\section{The DUMPAIR (dump pair) routine will list all references common to the two materials of interest.}

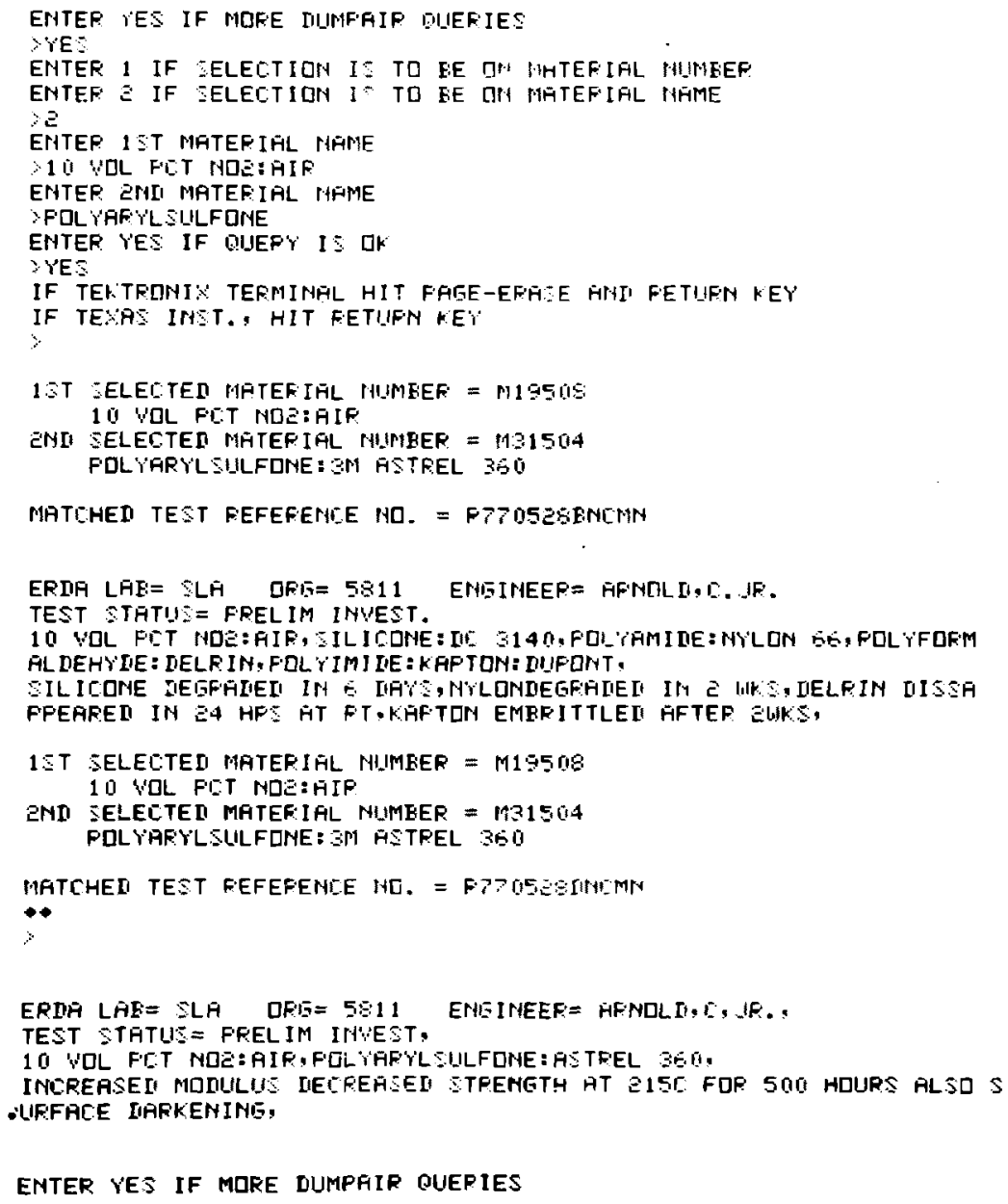




\begin{abstract}
ALLNAME routine provides an alphabetic listing of materials represented by the data bank. This routine automaticaliy reproduces a numerical list of materials. The computer program recognizes only an exact spelling of a name.
\end{abstract}

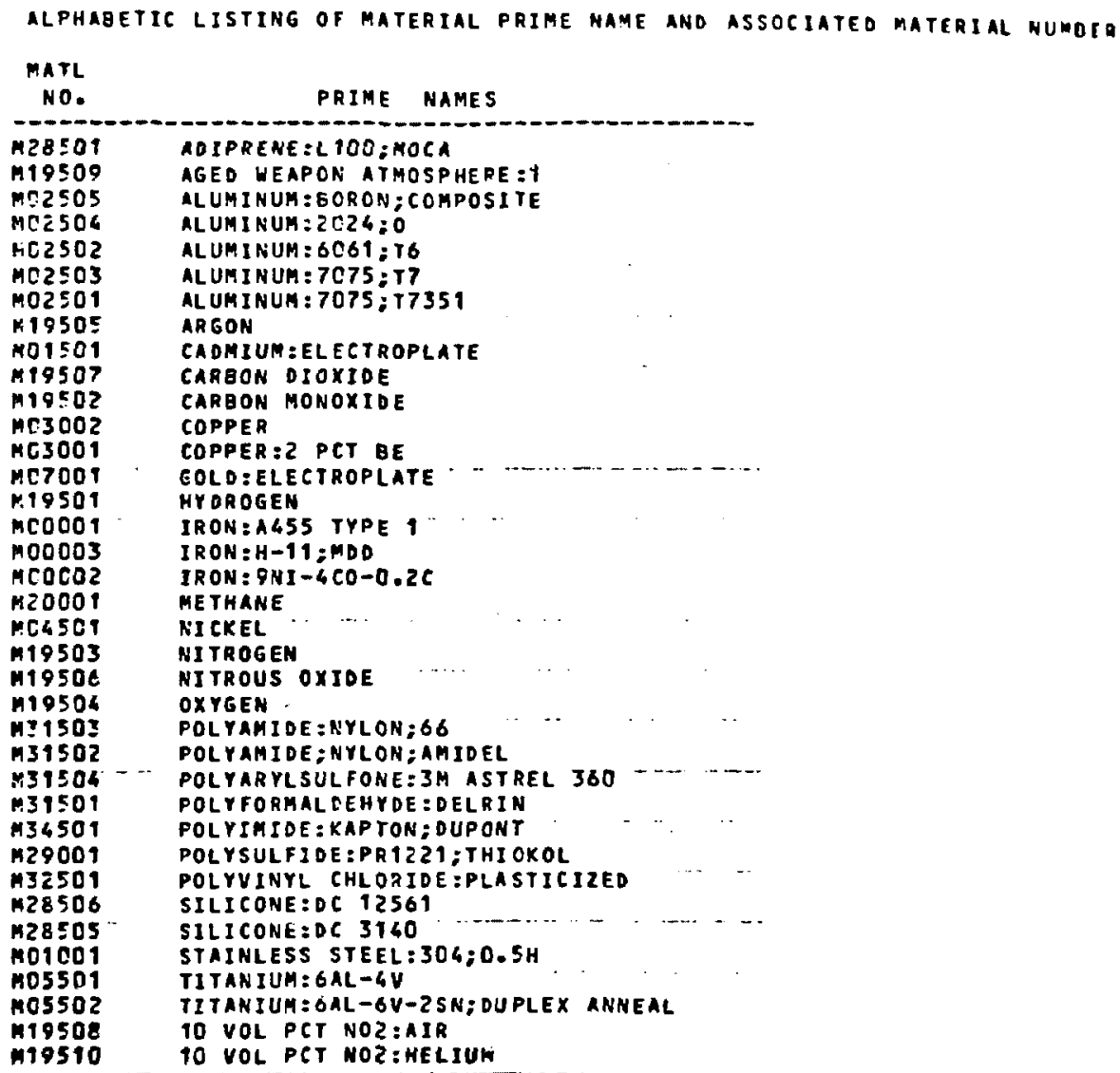


TABLE A-6

Batch Output ALLBAD-1

The batch output shown here, ALLBAD 1, lists all references indicating an incompatibility for each material represented in the data bank.

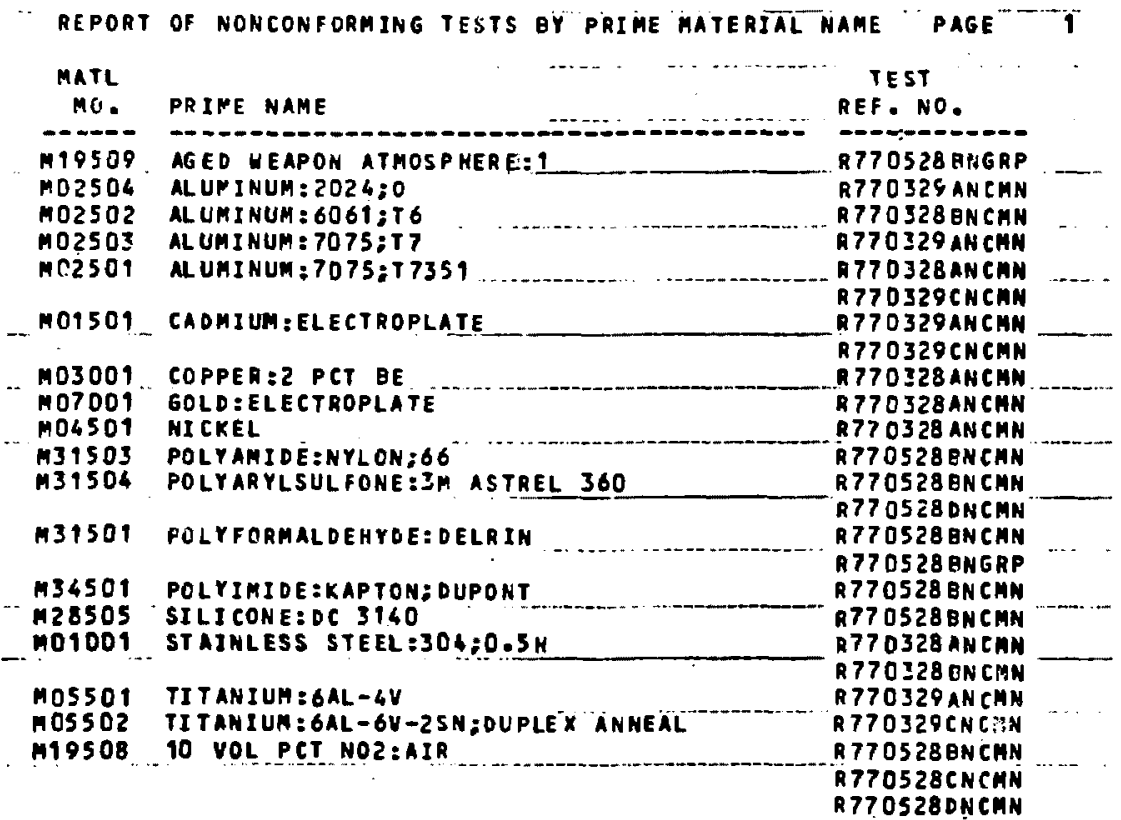


TABLE $A-7$

ALLBAD-2

\begin{abstract}
ALLBAD 2 routine lists all references indicating an incompatibility with a listing of all materials involved in the reference.
\end{abstract}

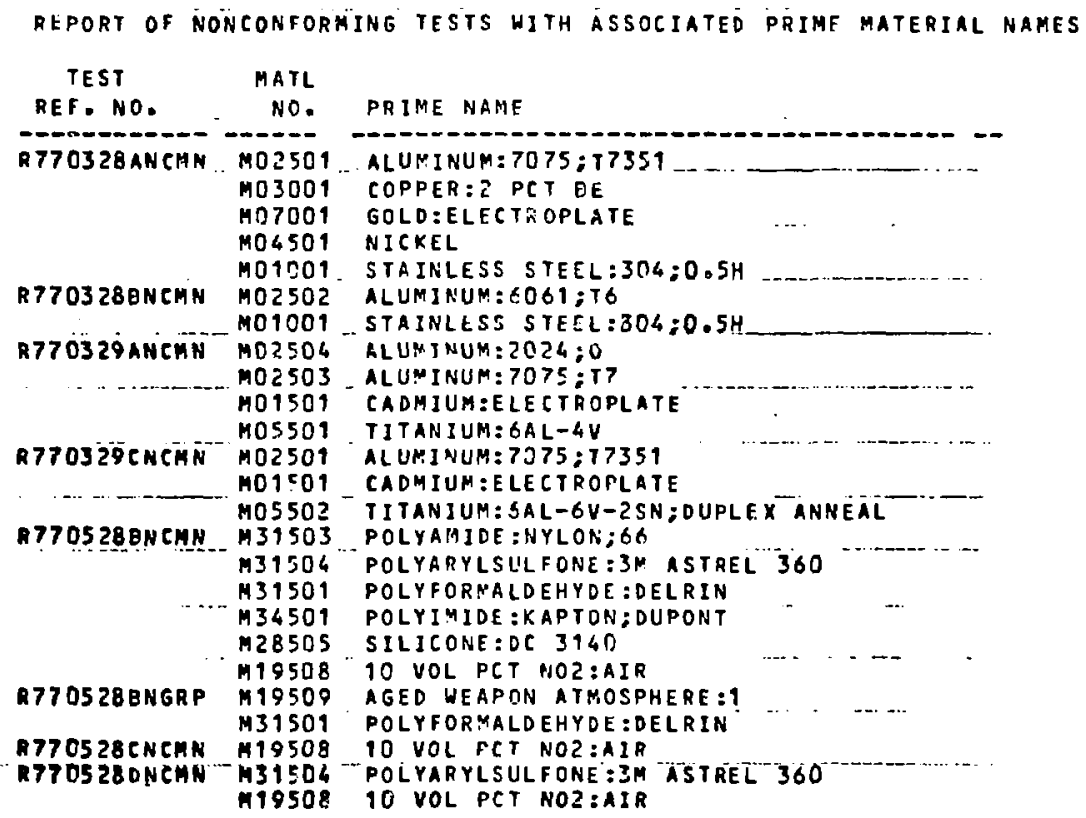


TABLE A-8

ALLAPPL

\begin{abstract}
ALLAPPL (all applications) routine lists each application represented by the data bank and a list of materials for which some information pertinent to that application has been entered in the data hank.
\end{abstract}

\title{
LISTINO OF MATERIALS USED ON EACH APPLICATZON
}

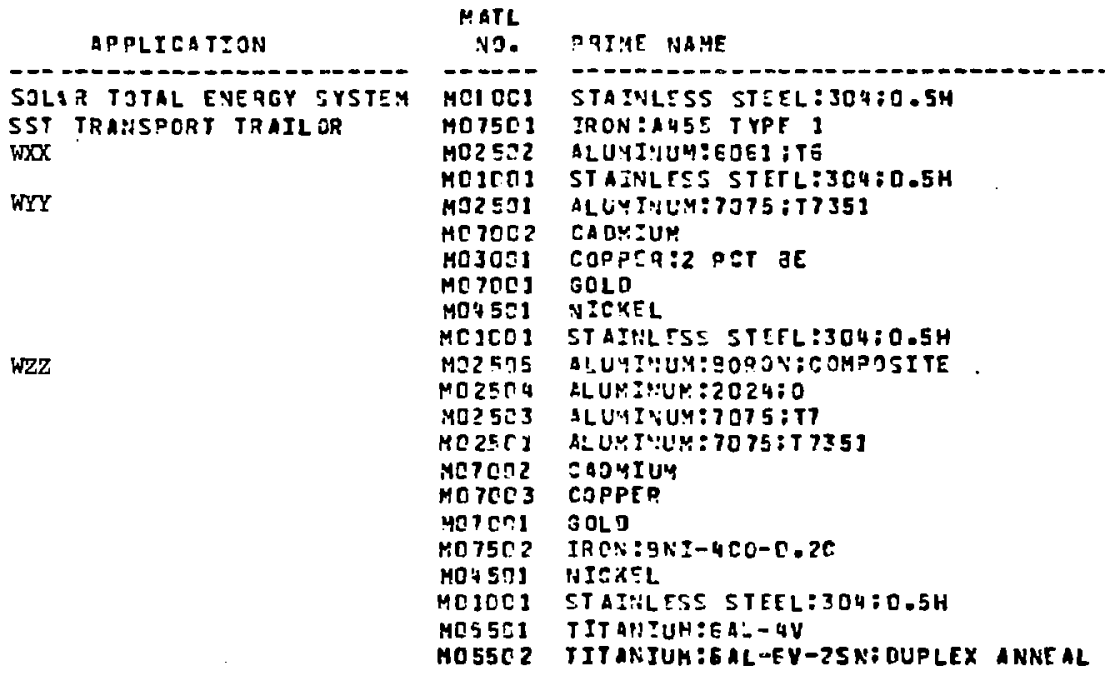


TABLE A -9

1) AIPCAT

The DLMPCAT (dump category) routine permits a query using up to three generic descriptors of a material. The descriptors used can be any combination generic names, forms, or functions.

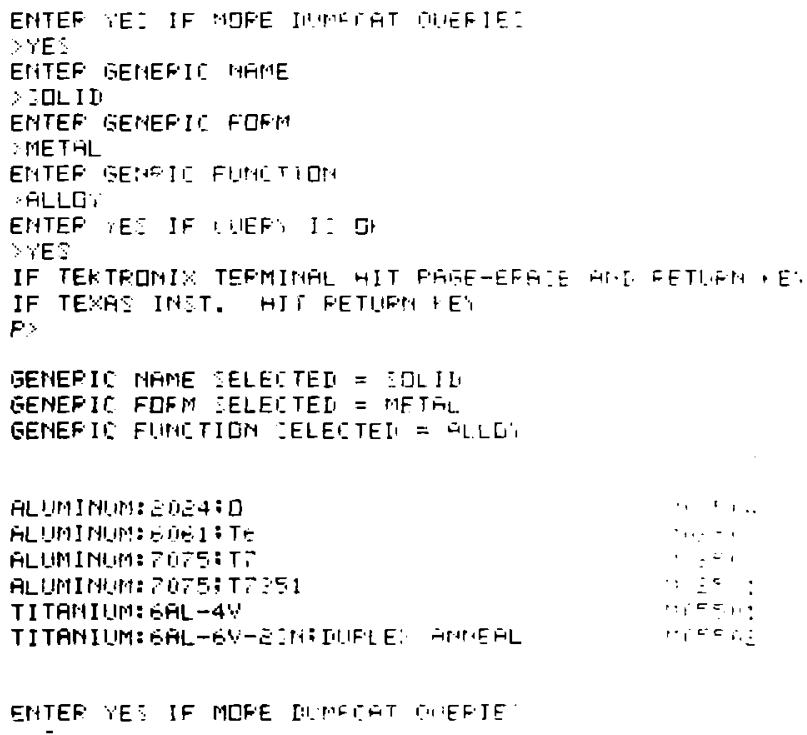


TABLE $\Lambda-10$

DIMPUSE*

The DUMPUSE routine will list ali materials having a common form or functional use in entry level five.

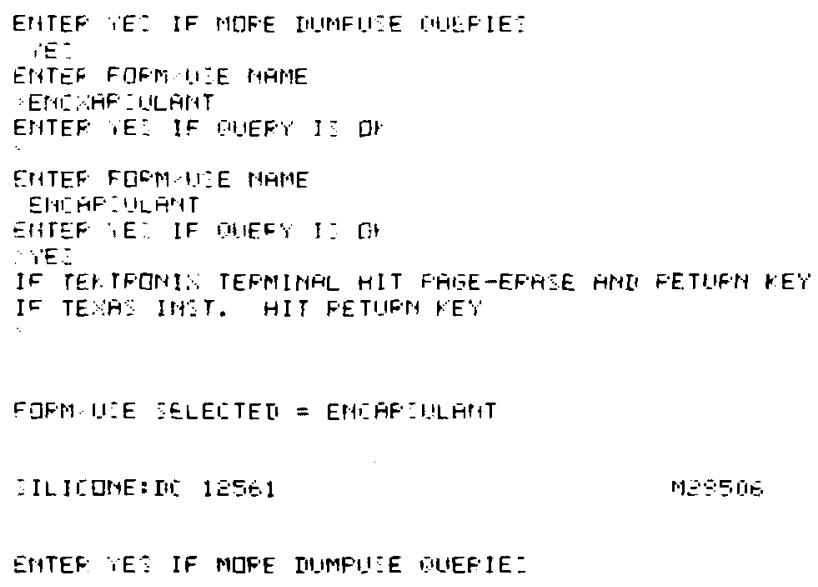


TABLE A-11

DUMPAPL

DUMPAPL (dump applications) is an interactive routine for obtaining a materials list represented by a single application.

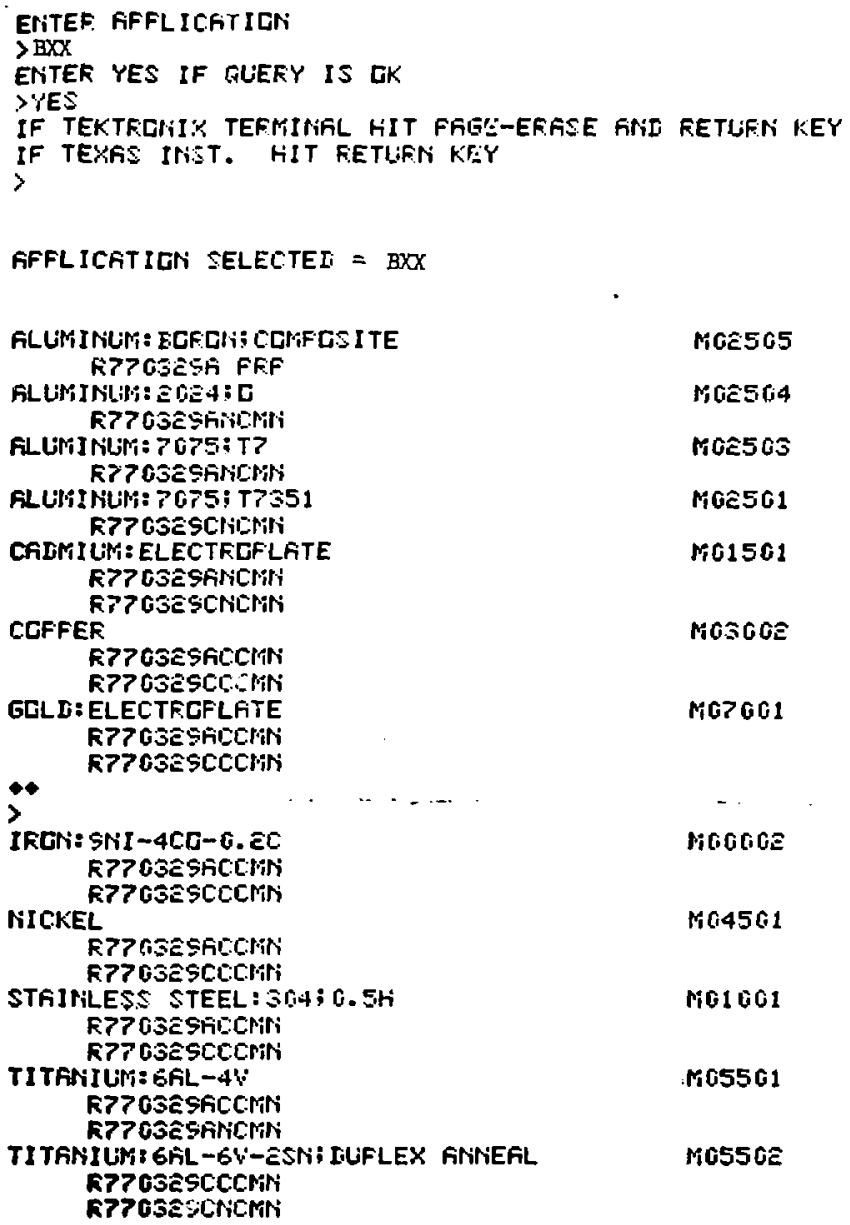

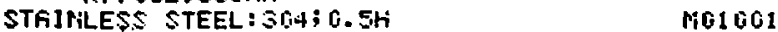

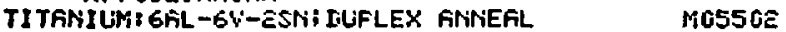

MGÉ5G5

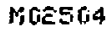

MGESGS

Moßs01

Mio1501

Mosoge

MOZGOI

Mgogoe

MG4501

M05501 


\section{APPENDIX B}

Materials Information Data Bank System (Includes a Data Input Flow Chart and Syatems Procedure) 


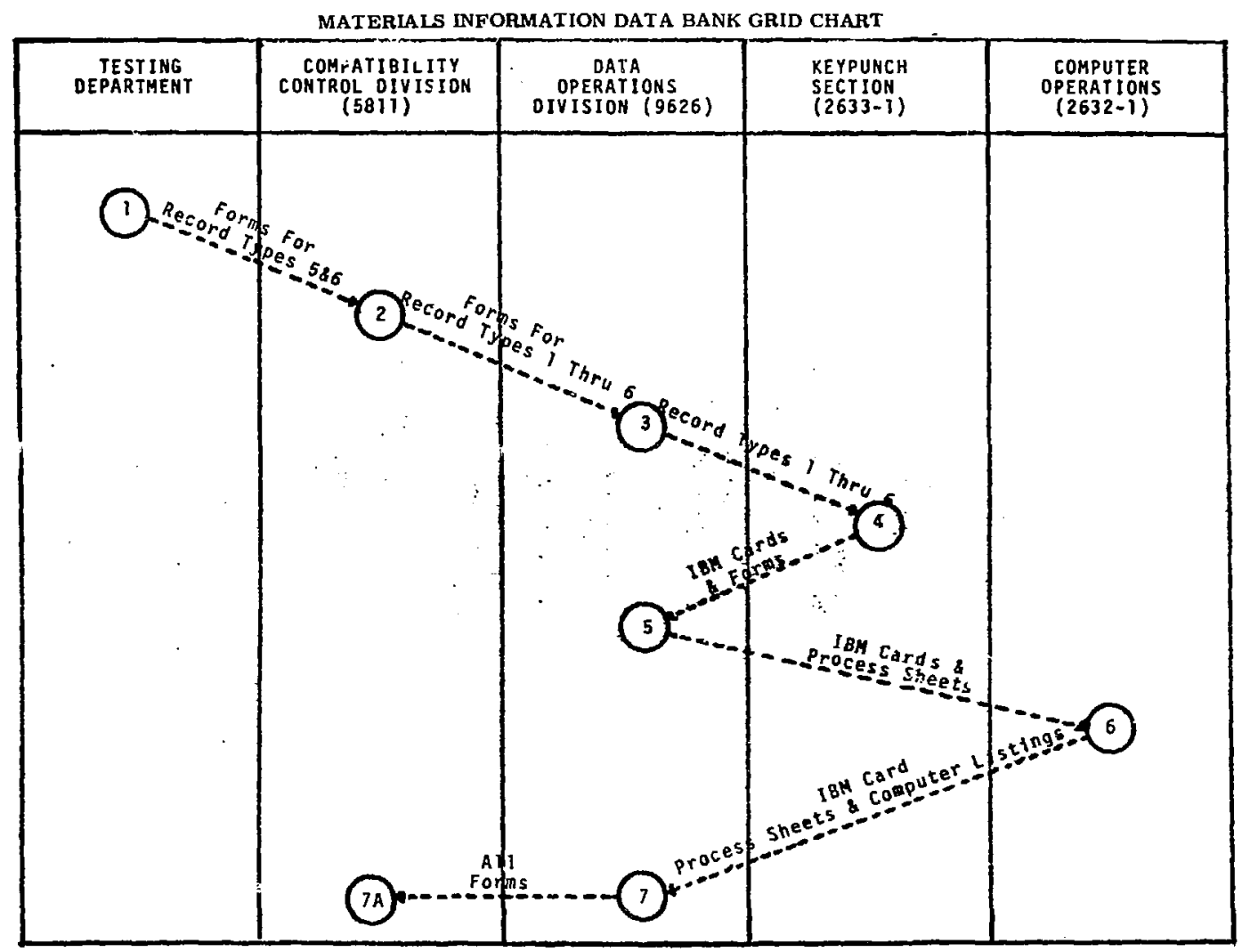

Figure B-1. MCSIS Data Input Flow Chart 
Responsibility

TEST ENGINLER

COMPATIBILITY CLERK

COMPATIBILITY COORDINATOR

COMPAT IBILITY CLERK

\section{Action}

1. On completion of test, completes a copy of TEST SUMMARY RECORD farm for all compatible materials and another copy for all incompatible materíals.

a. Fills in only the following data blocks:

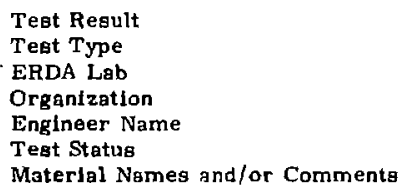

2. Completes ADDITIONS TO EXISTING MATERIAL RECORDS form for each material involved in the test.

a. Fille In only the following data blocks:

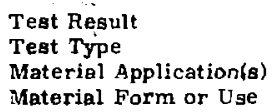

3. Attaches forma to a copy of the test report and forwarda to compatibllity clerk.

4. Verifteg the TEST SUMMARY and ADDITIONS TO EXISTING MATERIALS RECORDS forms for completness and accuracy.

5. Fills in material number on ADDITIONS TO EXISTING RECORDS form for each material name.

a. If materisl name has not been assigned a material number, sends forms to compatibility coordinator.

(1) Fills in NEW MATERIALS RECORD form for each new material name (record types 1 thru 4).

(2) Returns forms to compatibillty clerk.

6. Assigns new material numberg to new material names.

7. Records new materıal number in log book.

B. Assigns test reference document number to each TEST SUMMARY RECORD form (Record Type 6).

9. Records game test reference document number on each associated ADDITIONS TO EXISTING RECORDS form (Record Type 5). 
Responsibility

COMPATIBILITY CLERK

DATA OPERATIONS

CLERK

KEYPUNCH

DATA OPERATIONS CLERK

COMPUTER OPERATIONS CLERK
Action

10. Records test refirence document number(s) on test report document.

11. Fills copy of teat report by test reference document number.

12. Sends forms to data operations c lerk.

13. Reviews forms for completness.

B. If not $O K$, returns to compatibility clerk.

14. Prepares keypunch requegt.

a. Counts number of forms and marks on keypunch request.

15. Attaches forms to keypunch request and submits forms to keypunch.

16. Keypunches forms on $\mathrm{IBM}$ cards.

17. Returng forms and associated IBM cards to the data operations clerk.

18. Counts forms and verifies count on keypunch

request. If count does not agree contacts keypunch for missing forms.

19. Stores IBM cards in weekly work-in-process card flle.

20. Stores forms in weekly work-in-process forms files.

21. At end of week, takes cards in work-in-process file and marks with next batch number.

a. Submits cards to preliminary edit from the 9300 remote terminal.

b. Corrects errora and repeats step 21 a until all errors have been eliminated.

22. Prepares operations form 1108.

a. Fills in reel number of the next backup file.

23. Submits IBM cards and operations forms 1108 to computer operations clerk.

24. (See separate procedure for computer operations clerk.)

25. Returns IBM cards, opera'tons forms 1108, and computer liating to data operations clerk. 
Responsibility

DATA OPERATIONS CLIERK

COMPATIBILITY CLERK
Action

26. Checks to see if computer program ran to completions. If not, notifies computer programmer.

27. If run is OK. logs in new backup reel number.

2B. Examines computer update counts, If In error, notifles programmer.

29. Pxamines computer listing for edit rejects.

If edit rejected records

a. Pulls error cards from card deck (all record types). Also pulls associated forms from weekly work-in-process forms file.

b. Researches e.rors. Coordinates with compatibility clerk.

c. Corrects IBM cards.

d. Files corrected cards in weekly work-in-process card file.

e. Files forms in weekly work-in-process forms file.

30. Attaches oper tions form 1108 to computer listing and files in date order.

31. Files IBM cards in completed card file. Orders decks by batch number. Keeps the last five batches.

32. Returns those forms accepted by the edit to the compatibility clerk.

33. Files NEW MATERIALS RECORD forms (record types 1 through 4) by material number.

34. Attaches TEST SUMMARY RECORDS and ADDITIONS TO EXISTING RECORDS forms to the associated test report and files in test reference number order. 